\title{
PREPARATION AND CHARACTERIZATION OF POLYETHYLENE BASED GRAFT COPOLYMERS. APPLICATIONS IN THE IMMOBILIZATION OF ENZYMES
}

\author{
L.M. FERREIRA ${ }^{1}$, J.M.S. ROCHA ${ }^{2}$, M.E. ANDRADE' AND M.H. GIL ${ }^{2}$ \\ 'Physics, Nuclear and Technological Institute, ITN, P.O. Box 21, \\ 2685 SACAVÉM Codex, PORTUGAL
}

${ }^{2}$ Department of Chemical Engineering, Faculty of Science and Technology, University of Coimbra, PORTUGAL

\begin{abstract}
In the last few years new copolymeric supports for the immobilization of biological compounds have been developed. The graft copolymer polyethylene-g.co-hydroxyethyl methacrylate, partially hydrolyzed, has shown to be a very promising support for this purpose.

The more recent work in the preparation and characterization of this copolymer, as well as the immobilization of a lipase, is reported in this paper. Branches of poly(hydroxyethyl methacrylate) were grafted onto low density polyethylene by using gamma radiation. The influence of the presence and absence of air, as well as the monomer concentration on the yield of grafting were evaluated.

The obtained copolymers were characterized by DSC and FTIR. The influence of the support properties on the synthesis biocatalytic activity was detected.
\end{abstract}

\section{KEYWORDS}

Graft copolymers; Gamma radiation; Immobilization; Lipase.

\section{INTRODUCTION}

Graft copolymerization provides a general method for the modification of the physical and chemical properties of polymers, which can be used for the immobilization of biocatalysts. As part of such studies, graft copolymers of polyethylene (PE) were prepared and used for the immobilization of enzymes, other proteins and cells (Beddows et al, 1980 and 1982).

$\mathrm{PE}$ has been extensively used as a backbone for radiation grafting of different monomers. The preparation and characterization of polyethylene-g.co-hydroxyethyl methacrylate (PE-g.co-HEMA) is considered in this paper and used as a support for the immobilization of a fungal lipase.The lipase immobilization was done by the poly(hydroxyethyl methacrylate) branches, after partially hydrolyzed with aqueous solution (1M) of $\mathrm{NaOH}$, via spacer arms of 1,6 -diaminohexane, activated with glutaraldehyde.

\section{EXPERIMENTAL}

\section{Materials}

Low density $\left(\rho=0.915 \mathrm{~g} . \mathrm{cm}^{-3}\right.$ ) polyethylene (PE) was obtained from Neste Chemicals, Sines, Portugal, and was purified by extraction, in a soxhlet, with absolute ethanol for 6 hours. Then, it was dried to constant weight under vacuum at $40^{\circ} \mathrm{C}$. Hydroxyethyl methacrylate (HEMA) was obtained from 
Merck, Germany, and used without any purification. The 1-cyclohexyl-3-(2-morpholinoethyl)carbodiimide-metho-p-toluenesulfonate (CMC) was obtained from Sigma Chemical Co., St. Louis, USA, and lipase (from Mucor miehei) - Lipozyme $10000 \mathrm{~L}$, was kindly donated by NOVO Nordisk, Denmark.

\section{Procedures}

Particles of PE ( $2 \mathrm{~g}$ ) were dispersed in methanol $(\mathrm{MeOH})$ solutions of HEMA $\left(30 \mathrm{~cm}^{3}\right)$. The mixture was then irradiated with gamma radiation using a ${ }^{60} \mathrm{Co}$ source at $0.5 \mathrm{kGy} \cdot \mathrm{h}^{-1}$. Two monomer concentrations were used in this study $(5$ and $10 \% \mathrm{v} / \mathrm{v})$.

The influence of the presence and absence of air on the yield of grafting was evaluated. When the assays were carried out in the absence of air, the samples were deaerated by bubbling pure nitrogen and then, the ampoules containing the suspensions were sealed under vacuum.

After various times of irradiation, the bulk solutions containing a suspension of the grafted PE powder were transfered to methanol $(\mathrm{MeOH})$. The solids were filtered and washed thoroughly with $\mathrm{MeOH}$. The grafted products were filtered, washed and extracted with $\mathrm{MeOH}$ in a Soxhlet for 4 hours and then dried in vacuum at $40^{\circ} \mathrm{C}$.

To transform the poly(2-hydroxyethyl methacrylate) branches of the graft copolymers into the corresponding poly(methacrylic acid), portions of the copolymer $(1 \mathrm{~g})$ were refluxed with $25 \mathrm{~cm}^{3}$ of $1 \mathrm{M} \mathrm{NaOH}$ during 4 hours. The product was filtered, washed with water, with $1 \mathrm{M} \mathrm{HCl}$ and again with water.

To immobilize the lipase, $50 \mathrm{mg}$ of the copolymer were treated with an aqueous solution $\left(12 \mathrm{~cm}^{3}\right)$ of 1,6-diaminohexane $(1 \% \mathrm{v} / \mathrm{v})$ in the presence of $10 \mathrm{mg}$ of $\mathrm{CMC}$ at room temperature, under magnetic stirring, during 24 hours. The particles were then filtered and washed. In the second step the particles were re-suspended in $10 \mathrm{~cm}^{3}$ of glutaraldehyde aqueous solution $(5 \% \mathrm{v} / \mathrm{v})$, under magnetic stirring, at room temperature, for 30 minutes. The particles were filtered and washed again. The lipase was then immobilized in a third step by suspending these particles in $6 \mathrm{~cm}^{3}$ of phosphate buffer solution $(0.1 \mathrm{M}$, $\mathrm{pH} 7$ ) to which a volume of lipase solution, $0.4 \mathrm{~cm}^{3}$, was added. The reaction was carried out at $4^{\circ} \mathrm{C}$ for 18 hours. Finally the particles were filtered and washed under reduced pressure.

\section{Lipase esterification activity}

The direct synthesis of n-octyl oleate was chosen as a model esterification reaction to assay the activity of the immobilized lipase preparation. The reaction mixture typically comprised $5 \mathrm{~cm}^{3}$ of n-octanol and $1.5 \mathrm{~cm}^{3}$ of oleic acid without the addition of any other organic solvent. The synthesis reaction was initiated with the addition of the immobilized lipase preparation and progressed under magnetic stirring at $37^{\circ} \mathrm{C}$. The time course of the reaction was followed for 24 hours. At different time intervals $0.5 \mathrm{~cm}^{3}$ were sampled and diluted in $10 \mathrm{~cm}^{3}$ of ethanol and the amount of free fatty acid still present at the reaction mixture was determined by titrimetric analysis with $0.1 \mathrm{M} \mathrm{KOH}$ in ethanol, using phenolphtalein as the end point indicator. Samples were also withdrawn before the start of the reaction, i.e., before the addition of the biocatalyst, and the free fatty acid content determined. The ester content was easily quantified from the amount of fatty acid remaing in each sample.

\section{DSC analysis}

The DSC experiments were carried at $10^{\circ} \mathrm{C} / \mathrm{min}$ in $\mathrm{N}_{2}$ atmosphere using a DSC Polymer Laboratories equipment.

\section{FTIR analysis}

The FTIR analysis were determined using a FTIR equipment from Nicolet Magna - IR ${ }^{\mathrm{TM}}, 750$. 


\section{RESULTS AND DISCUSSION}

The grafting reactions were carried out in methanol because this is a good solvent for both the monomer and the homopolymer, poly(HEMA), and by this way, Tromnsdorff effects can be avoided. In all the radiation induced copolymerizations, no viscous solutions were obtained. The total concentrations of the monomer in the bulk medium were 5 or $10 \%(\mathrm{v} / \mathrm{v})$, respectively. The reactions were carried out in the presence and in the absence of air. The grafting degree was given by the following equation:

$$
\% \text { grafting }=\frac{M_{f}-M_{i}}{M_{i}} \times 100
$$

where:

$$
\begin{aligned}
& M_{f}=\text { final mass of the copolymer (PE-g.co-HEMA) } \\
& M_{i}=\text { initial mass of the polymer (PE) }
\end{aligned}
$$

\section{Effect of the monomer concentration}

The effect of the monomer concentration was studied at an average radiation rate of $0.5 \mathrm{kGy} \cdot \mathrm{h}^{-1}$. The grafting degree of HEMA onto PE with the irradiation time increasing, for two bulk monomer concentrations, in the presence and absence of air, is shown in Figurel.
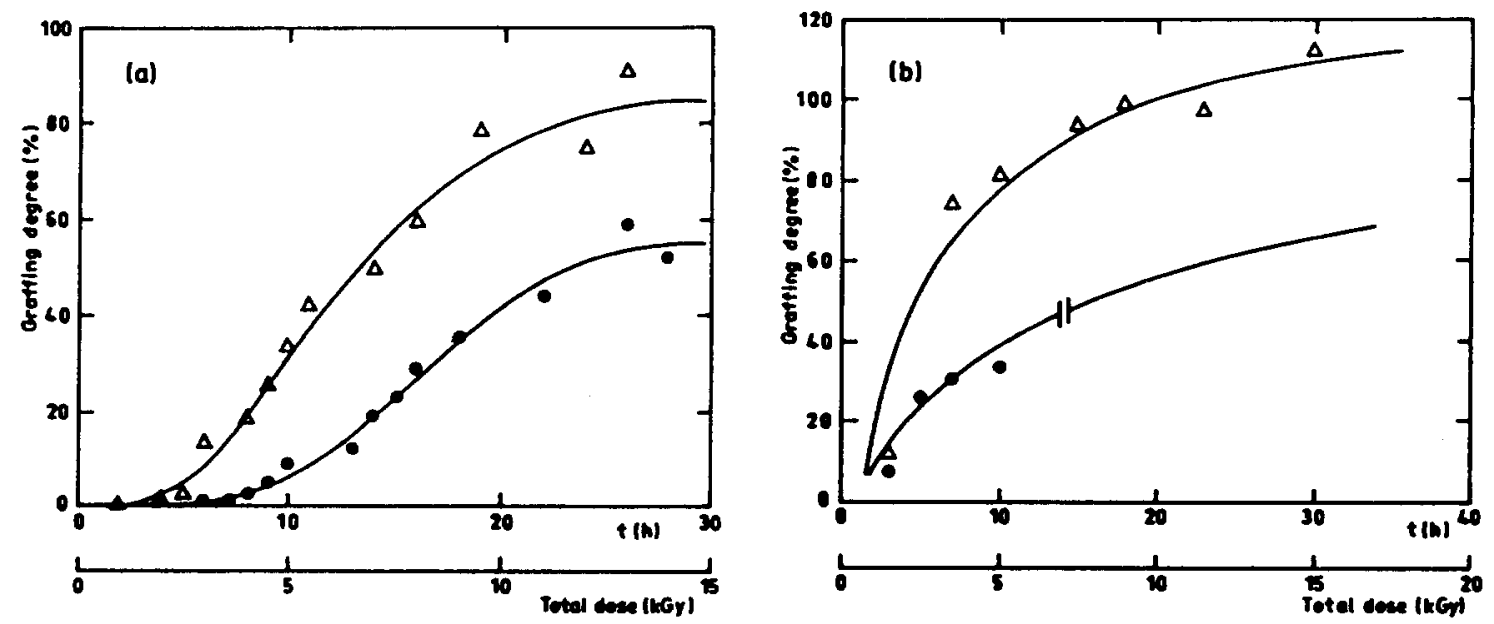

Figure 1: Influence of the irradiation time (or total accumulated dose of radiation) in the percentage of grafting. for two monomer concentrations $(\bullet-[\mathrm{HEMA}]=5 \% \mathrm{v} / \mathrm{v} ; \Delta-[\mathrm{HEMA}]=10 \% \mathrm{v} / \mathrm{v})$;

(a) in the presence of air

(b) in the absence of air

In both cases, the grafting degree increases with the monomer concentration and with the time of irradiation. However, the yield of grafting (as well as the initial rate of the copolymerization reaction) is higher in the absence of air. After 30 hours of irradiation, the percentage of grafting in the absence of air is nearly $30 \%$ higher than in its presence. The radiation grafting of HEMA onto PE is still under research with the aim to evaluate the grafting kinetic parameters, for the production of graft copolymers in a reproducible way, and suitable for the immolilization of enzymes. 
For lipase immobilization, samples of copolymer obtained from a $10 \%(\mathrm{v} / \mathrm{v})$ monomer solution and irradiated in the presence of air were chosen. The reason was just because they were the first samples of PE-g.co-HEMA obtained and they had higher yields of grafting (90-120\%) at the end of the grafting reaction. Other studies has shown that the reduction of the average PE particles size also favoured the grafting yield.

\section{DSC analysis}

The DSC thermal analysis was used to provide an indication of the changes in structural order of PE chains which can be brought about by grafting with HEMA and by hydrolysis of the subsquent grafts. Such changes can be of assistance in improving the access of enzymes and in the modification of the hydrophylicity of the support.

Table 1: Effect of the grafting yield of the copolymer PE-g.co-HEMA on its structure.

\begin{tabular}{ccc}
\hline $\begin{array}{c}\text { Yield of } \\
\text { grafting } \\
(\%)\end{array}$ & $\begin{array}{c}\text { Endothermic transition } \\
\text { temperature } \\
\left({ }^{\circ} \mathrm{C}\right)\end{array}$ & $\begin{array}{c}\text { Melting } \\
\text { enthalpy } \\
\left(\mathrm{J} \cdot \mathrm{g}^{-1}\right)\end{array}$ \\
\hline 0 & 104.7 & 97.6 \\
79 (i) & 104.3 & 60.2 \\
79 (ii) & 106.9 & 50.2 \\
105 (i) & 103.5 & 50.4 \\
105 (ii) & 106.7 & 41.7 \\
\hline
\end{tabular}

(i) not hydrolyzed

(ii) after 4 h of hydrolysis

Table 1 contains data concerning the thermal stability of the materials studied. We can observe that the melting enthalpy decreases with the increasing yield of grafting and with the hydrolysis of the branches. This melt behaviour is related to a disorder in the PE backbone brought about by grafting and subsequent hydrolysis, i.e. a reduction in the copolymer cristalinity.

\section{Characterization by FTIR}

The PE, the copolymer and the hydrolyzed copolymer were characterized by FTIR. Figure 2 shows that the bands presented in Table 2 increase after the hydrolysis, which suggests that $-\mathrm{COOH}$ groups are being formed and involved in hydrogen bonds with the water present in the more hydrophylic material.

Table 2: Absorbance bands correspondents to the main functional groups present in the materials characterized by FTIR.

\begin{tabular}{|c|c|c|}
\hline Bands & Functional Group & \\
\hline $1050-1200$ & & (in esters) \\
\hline 1250 & & (in carboxylic acids) \\
\hline 1740 & & (in esters) \\
\hline $3200-3600$ & $-\mathrm{OH}$ & (hydrogen bond) \\
\hline
\end{tabular}




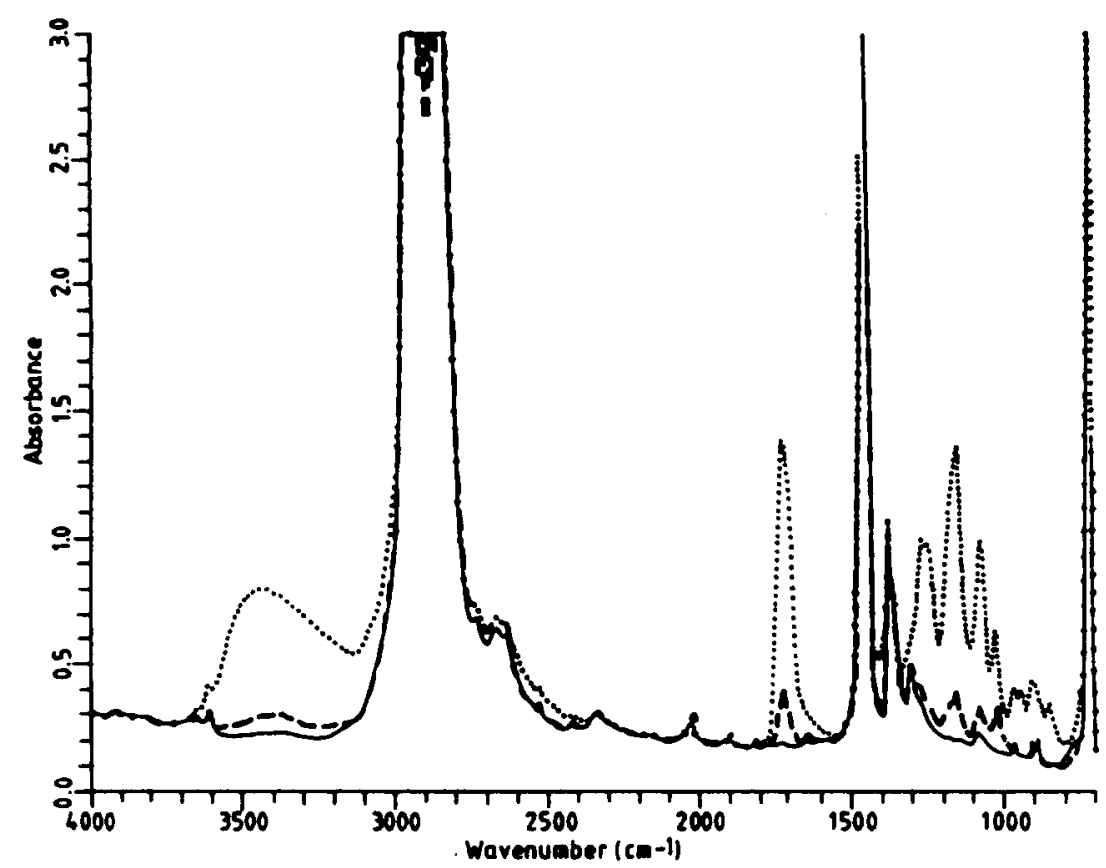

Figure 2: FTIR spectrum of PE, copolymer and hydrolyzed copolymer;

( - PE low density;

... PE-g.co-HEMA 97\% grafting;

... the same copolymer after hydrolysis)

\section{Immobilization of lipase}

The hydrolyzed samples of PE-g.co-HEMA with different percentage of grafting were used to immobilize the lipase. The coupling through the carboxylic groups was carried out via 1,6-diaminohexane as a spacer arm, activated with glutaraldehyde. The immobilized lipase was used as a biocatalyst for the synthesis of n-octyl oleate, from oleic acid and octanol, in the absence of solvents. In previous experiences, the influence of particle size of the PE on the lipase activity was evaluated and the best results were obtained with particles in the range of $150-250 \mu \mathrm{m}$. Consequently, the assays for the enzymatic synthesis were carried out using particles within this range. The results obtained are shown in Table 3, which suggest that the enzymatic activity is dependent on the grafting degree and that this support is very promising for the covalent linkage of lipase.

Table 3: Enzymatic synthesis of n-octyl oleate.

(PE particles average size: $150-250 \mu \mathrm{m} ; 4$ hours of hydrolysis; $0.4 \mathrm{~cm}^{3}$ of Lipozyme $10000 \mathrm{~L} / 50 \mathrm{mg}$ of PE-g.co-HEMA; reaction mixture: $5 \mathrm{~cm}^{3}$ of octanol $+1.5 \mathrm{~cm}^{3}$ of oleic acid; $\mathrm{T}=37^{\circ} \mathrm{C}$; B.S.T.R.).

\begin{tabular}{ccc}
\hline $\begin{array}{c}\text { Grafting degree } \\
(\%)\end{array}$ & $\begin{array}{c}\text { Initial rate } \\
\left(\mathrm{mol} . \mathrm{I}^{-1} \cdot \mathrm{h}^{-1}\right)\end{array}$ & $\begin{array}{c}\text { Ester synthesis yield } \\
\text { after 10 hours (\%) }\end{array}$ \\
\hline 91 & 0.076 & 74.8 \\
100 & 0.130 & 83.8 \\
120 & 0.145 & 82.1 \\
\hline
\end{tabular}




\section{CONCLUSIONS}

The results presented in this paper suggest that:

1. The presence of air decreases the yield of grafting when branches of poly(HEMA) are linked to PE as the backbone.

2. The modifications of PE by the grafting reaction decrease its cristalinity.

3. This support is very promising for covalent linkage of lipases leading to biocatalysts very good for ester synthesis.

Acknowledgements- Part of this work has been supported by Sub-Program Science and Technology of the Second RTD Framework Programme, and by the Nuclear and Technological Institute.

\section{REFERENCES}

Beddows C.G., Gil M.H. and Guthrie J.T. (1980) The Immobilization of BSA to Maleic Anhydride Block Copolymers. Polymer Bull, , 3, 645-653

Beddows C.G., Gil M.H. and Guthrie J.T. (1982) The Immobilization of Enzymes, BSA and Phenylpropylamines to Poly(acrylic acid) polyethylene Based Copolymers. Biotechnol. Bioeng., 14, 1371-1387 